\title{
Is early goal-directed therapy associated with a higher risk of adverse events?
}

\author{
Ahmad Sabry Saleh *
}

\begin{abstract}
The Japanese Clinical Practice Guidelines for Management of Sepsis and Septic Shock 2016 suggested against the use of the early goal-directed therapy (EGDT) in patients with septic shock. This recommendation was based on the three large-scale trials (ProCESS, ARISE, and ProMISe). Although the three trials showed no difference in mortality between EGDT and usual care, the guidelines determined that the potential harms presented by EGDT likely outweigh its potential benefits. On the contrary, analysis of data from the three trials showed an approaching statistical significance lower risk of serious adverse events in the EGDT group compared to usual care (risk difference $=-1 \%, 95 \%$ confidence interval; $-2 \%$ to $0 \%, P=0.05$ ). EGDT may still be beneficial in patients with high disease severity and low central venous oxygen saturation, especially when managed by less experienced staff.
\end{abstract}

Keywords: Septic shock, Early-goal directed therapy, Usual care, Serious adverse events

\section{Dear Editor,}

I read with great interest the English edition of the Japanese Clinical Practice Guidelines for Management of Sepsis and Septic Shock 2016 published recently in the Journal of Intensive Care [1]. Although the guidelines are primarily tailored to the Japanese context, it represents an excellent summary of the current literature and thus it is of great interest to intensivists from around the globe. I would like to discuss a few points regarding section CQ7: Initial resuscitation/inotropes.

First, the guidelines suggested against the use of the early goal-directed therapy (EGDT) when performing initial resuscitation in patients with sepsis or septic shock. EGDT is a 6-h resuscitation protocol for the administration of intravenous fluids, vasopressors, inotropes, and red-cell transfusion to achieve pre-specified targets for central venous pressure, arterial blood pressure, urine output, and central venous oxygen saturation $\left(\mathrm{ScvO}_{2}\right)$ [2]. This recommendation was based on the three large-scale randomized controlled trials (RCTs); ProCESS [3], ARISE [4], and ProMISe [5] reported in 2014 and 2015. Although the three RCTs showed no significant difference in mortality between EGDT and usual

\footnotetext{
* Correspondence: sabryccm@gmail.com

Intensive Care Unit, Okba Ben Nafee Hospital, 45 street, el-Asafra, Alexandria 21539, Egypt
}

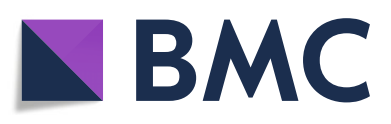

(c) The Author(s). Open Access This article is distributed under the terms of the Creative Commons Attribution 4.0 International License (http://creativecommons.org/licenses/by/4.0/), which permits unrestricted use, distribution, and reproduction in any medium, provided you give appropriate credit to the original author(s) and the source, provide a link to the Creative Commons license, and indicate if changes were made. The Creative Commons Public Domain Dedication waiver (http://creativecommons.org/publicdomain/zero/1.0/) applies to the data made available in this article, unless otherwise stated. potential harms presented by EGDT likely outweigh its potential benefits and explained their rationale as follows: "Dobutamine dosages and the quantity of blood transfused increased significantly in the EGDT group, and due to the increased frequency of arrhythmias associated with dobutamine, greater overall risk of side effects associated with transfusions, and increased time and quantity of work required of hospital staff, it is possible that compliance with EGDT may increase the risk of harm (burden) faced by patients" [1].

The notion that EGDT may increase the risk of harm to patients is rather speculative and not supported by clinical evidence or patients' data. On the contrary, pooled data from the three RCTs (Fig. 1) showed an approaching statistical significance lower risk of serious adverse events (SAEs) in the EGDT group compared to usual care (risk difference $=-1 \%, 95 \%$ confidence interval; $-2 \%$ to $0 \%, P=0.05)$. SAEs were uniformly defined among the three RCTs as "any untoward medical occurrence that: (1) results in death, (2) is life-threatening, (3) requires in-patient hospitalization or prolongation of existing hospitalization, (4) results in persistent or significant disability/incapacity, (5) is a congenital anomaly/ birth defect, or (6) other adverse event considered serious by medical judgment" [3-5]. 


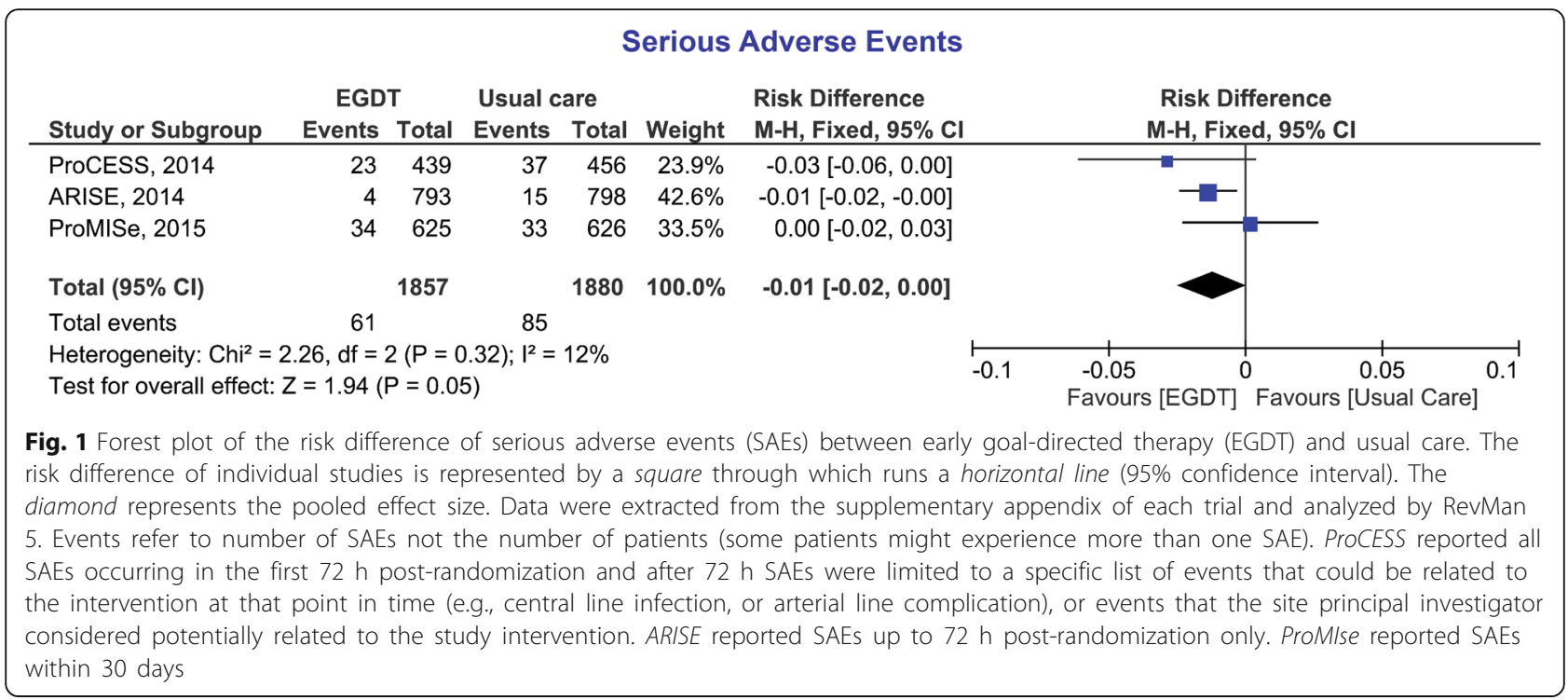

Second, the guidelines provided some contradictory statements. Despite the recommendation against EGDT, the guidelines provided an expert consensus statement that either $\mathrm{ScvO}_{2}$ or lactate clearance may be used as indicators of initial resuscitation (CQ7-8). And suggested that Dobutamine is used in septic shock when cardiac function remains diminished, and maintenance of hemodynamics is insufficient despite adequate fluid resuscitation and noradrenaline administration (CQ7-12) [1]. Both $\mathrm{ScvO}_{2}$ monitoring and Dobutamine are cardinal components of the EGDT. $\mathrm{ScvO}_{2}$ monitoring (with the subsequent use of Dobutamine and red-cell transfusion to correct $\mathrm{ScvO}_{2}$ ) was the only intervention not allowed by study protocol in the usual care group in the three RCTs [3-5]. Thus, the only conclusion we could draw from the three RCTs is that catheter placement for continuous $\mathrm{ScvO}_{2}$ monitoring is not necessary in every patient presented by septic shock. However, the three RCTs could not answer the question of whether targeting $\mathrm{ScvO}_{2}$ of $\geq 70 \%$ is an effective intervention or not as the most of the patient were at target $\mathrm{ScvO}_{2}$ on presentation (initial mean $\mathrm{ScvO}_{2}$ was $71 \%, 72 \%$, and $70 \%$ in the ProCESS [3], ARISE [4], and ProMISe [5], respectively).
Until future trials focusing on the subgroup of patients with low $\mathrm{ScvO}_{2}$ is conducted, the evidence from the original EGDT trial [2] which recruited patients with low $\mathrm{ScvO}_{2}$ (mean 49\%) is enough to consider the use of Dobutamine and red cell transfusion to correct $\mathrm{ScvO}_{2}$ to decrease mortality.

Finally, I totally agree with the guidelines statement that "the treatment of sepsis can vary significantly depending on the level of care offered by a given facility and the level of knowledge and skills of the attending physician and staff". The Three RCTs [3-5] were primarily conducted in academic/tertiary care centers in high-income countries and included patients with low severity septic shock who rapidly responded to therapy. Even though, their usual care was associated with a trend toward higher risk of SAEs. The question here is, what would be the situation in less equipped facilities or with physicians with less expertise? In fact, multiple issues have been raised regarding the external validity of the three trials suggesting that EGDT may still be beneficial in patients with high disease severity and low $\mathrm{ScvO}_{2}$, especially when managed by less experienced staff who may appreciate using simple protocols $[6,7]$.

Response to Dr. Saleh: "Is early goal-directed therapy associated with a higher risk of adverse events?” Yasuyuki Kakihana', Asako Matsushima² and Osamu Nishida ${ }^{3}$

\footnotetext{
'Department of Emergency and Intensive Care Medicine-Kagoshima, University Graduate School of Medical and Dental Sciences, Kagoshima, Japan

2Department of Advancing Acute Medicine, Nagoya University Graduate School of Medical Sciences, Nagoya, Japan

${ }^{3}$ Department of Anesthesiology and Critical Care Medicine, Fujita Health University School of Medicine-Toyoake, Aichi, Japan
} 
We read the letter to the editor from Dr. Saleh with great interest. For the assessment of the CQ7-1 "Is early goal-directed therapy (EGDT) recommended for initial resuscitation in patients with sepsis or septic shock?", three randomized controlled trials (RCTs) [3-5] were identified based on a search of the PubMed database and were used in the final analysis. Our analyses showed no significant difference in mortality between EGDT and the standard treatment (90-day mortality rate: risk ratio 0.98 [95\% confidence interval $\{\mathrm{CI}\} \quad 0.88-1.10]$; 28-day mortality rate: risk ratio 0.98 [95\% CI $0.84-1.13]$ ] [1]. Regarding the benefit-risk balance, dobutamine dosages and the quantity of blood transfused were significantly increased in the EGDT group compared to the usual-care group $[3,4]$, and due to the increased frequency of arrhythmias associated with dobutamine and greater overall risk of side effects associated with transfusions, it is possible that compliance with EGDT may increase the risk of harm (burden) faced by patients. As Dr. Saleh suggested first, however, the pooled data from the three RCTs show an approaching statistical significance lower risk of serious adverse events (SAEs) in the EGDT group compared to the usual-care group (risk difference $=-1 \%, 95 \% \mathrm{CI}-2-0 \%, P=0.05)$. We therefore examined the data on the SAEs and AEs of the three RCTs again in detail and obtained the following results: In the ProCESS trials, reports of potential SAEs (excluding death) were rare and did not differ significantly across groups, with 23 events (5.2\%) reported in the EGDT group and 37 (8.1\%) in the usual-care group [3]; in the ProMISe trials, there was no significant between-group difference in the number of SAEs, with 34 events (5.4\%) reported in the EGDT group and 33 $(5.3 \%)$ in the usual-care group and at least 1 SAE reported among 30 patients $(4.8 \%)$ in the EGDT group and 26 patients $(4.2 \%)$ in the usual-care group $(P=0.58)$ [5]; a significant difference in the number of SAEs was observed only in the ARISE trials, with 4 events $(0.5 \%)$ reported in the EGDT group and $15(1.9 \%)$ in the usual-care group, although there was no significant between-group difference in the number of patients with $\geq 1 \mathrm{AE}$ (including SAEs) (56 patients [7.1\%] in the EGDT group and 42 patients [5.3\%] in the usual-care group; $P$ $=0.15$ ) [4]. Special precautions should be taken when interpreting the findings for SAEs in the ARISE trials, as (1) the number of SAEs in the ARISE trials was too small for a comparison with those of the other RCTs (ProCESS and ProMISe), and (2) the reason for the large difference between the number of SAEs and the number of AEs (including SAEs) in the ARISE trial was unclear. SAEs may develop less frequently in the EGDT group than in the usual-care group, as suggested by Dr. Saleh.

Second, Dr. Saleh claimed that until future trials focusing on the subgroup of patients with a low $\mathrm{ScvO}_{2}$ are conducted, the evidence from the original EGDT trial [2] that recruited patients with a low $\mathrm{ScvO}_{2}$ (mean 49\%) was sufficient to support the consideration of the use of dobutamine and red-cell transfusion to correct the $\mathrm{ScvO}_{2}$ in order to reduce mortality [7]. Because the serum lactate levels and $\mathrm{ScvO}_{2}$ are important for both assessing the oxygen transport capacity in tissues and as a marker of tissue hypoperfusion [8, 9], it is suggested that either factor $\left(\mathrm{ScvO}_{2}\right.$ or lactate clearance) may be used as an indicator of initial resuscitation [10]. Recently, a meta-analysis of individual patient data from the three recent trials (ProCESS, ARISE, ProMISe) was designed prospectively to improve the statistical power and explore the heterogeneity of the treatment effect of EGDT. The results showed that there was no evidence of a benefit associated with EGDT in the subgroups with the most severe septic shock, including those with a serum lactate level of $\geq 4.1 \mathrm{mmol} / \mathrm{L}$ (mean, $6.7 \mathrm{mmol} / \mathrm{L}$ ), those who presented with both hypotension and hyperlactatemia (mean systolic blood pressure, $89 \mathrm{mmHg}$; mean serum lactate level, $6.7 \mathrm{mmol} / \mathrm{L}$ ), those in the upper third of APACHE II scores (mean score, 24.6), and those in the upper third of predicted risk of death [11]. We therefore cannot conclusively say that EGDT is beneficial for the most severe septic shock patients with hyperlactatemia $\left(\mathrm{ScvO}_{2}\right.$ may be low).

Even if EGDT was associated with a lower incidence of SAEs than the usual-care and could be managed by less experienced staff who might appreciate using simple protocols, the recommendations for $\mathrm{CQ7}^{-1}$ in our guidelines remain unchanged. One of the most important principles to understand in the management of these complex patients is the need for a detailed initial assessment and ongoing reevaluation of the response to treatment. The use of CVP alone to guide fluid resuscitation, which is required by the EGDT protocol proposed by Rivers et al. [2], can no longer be justified [12] because the ability to predict a response to a fluid challenge when the CVP is within a relatively normal range (8$12 \mathrm{mmHg}$ ) is limited [13], and some patients treated with EGDT develop subsequent fluid overload, which may be associated with worse outcomes [14]. Dynamic measures of assessing whether or not a patient requires additional fluid have been proposed in an effort to improve fluid management and have demonstrated better diagnostic accuracy at predicting those patients who are likely to respond to a fluid challenge by increasing stroke volume. Furthermore, in recent years, the "hour-1 bundle" has been recommended, in which obtaining blood for measuring lactate and blood cultures, administering fluids and antibiotics, and in the case of life-threatening hypotension, initiating vasopressor therapy should all be begun immediately [15]. 
In their review, Nguyen et al. [6] stated that in this era of global reductions in sepsis mortality, clinicians should view EGDT as a verb (series of actions) rather than a noun. Thus, taking over the basic concept of EGDT to promptly improve the hypoperfusion of tissues but in keeping with the change in the new era, achieving the target value within $1 \mathrm{~h}$ (not $6 \mathrm{~h}$ ) may require developing a new version of EGDT (modified EGDT) that not only selects dynamic indices instead of CVP to predict fluid responsiveness but also avoids the fluid overload following initial resuscitation.

\section{Abbreviations}

EGDT: Early goal-directed therapy; RCT: Randomized controlled trial; SAEs: Serious adverse events; $\mathrm{SCVO}_{2}$ : Central venous oxygen saturation

\section{Acknowledgements}

Not applicable.

\section{Funding}

None.

\section{Availability of data and materials}

All data generated or analyzed during this study are included in this published article.

\section{Authors' contributions}

AS drafted the manuscript, performed the data analysis and approved the final manuscript.

\section{Ethics approval and consent to participate}

Not applicable.

\section{Consent for publication}

Not applicable.

\section{Competing interests}

The author declares that he has no competing interests.

\section{Publisher's Note}

Springer Nature remains neutral with regard to jurisdictional claims in published maps and institutional affiliations.

Received: 10 September 2018 Accepted: 1 November 2018

Published online: 26 November 2018

\section{References}

1. Nishida O, Ogura H, Egi M, et al. The Japanese clinical practice guidelines for management of sepsis and septic shock 2016 (J-SSCG 2016). J Intensive Care. 2018;6:7.

2. Rivers E, Nguyen B, Havstad S, et al. Early goal-directed therapy in the treatment of severe sepsis and septic shock. N Engl J Med. 2001;345(19): 1368-77.

3. ProCESS Investigators, Yealy DM, Kellum JA, et al. A randomized trial of protocol-based care for early septic shock. N Engl J Med. 2014;370(18): 1683-1693.

4. Arise Investigators. Anzics clinical trials group, Peake SL, et al. goal-directed resuscitation for patients with early septic shock. N Engl J Med. 2014; 371(16):1496-506.

5. Mouncey PR, Osborn TM, Power GS, et al. Trial of early, goal-directed resuscitation for septic shock. N Engl J Med. 2015:372(14):1301-11.

6. Nguyen $\mathrm{HB}$, Jaehne AK, Jayaprakash $\mathrm{N}$, et al. Early goal-directed therapy in severe sepsis and septic shock: insights and comparisons to ProCESS, ProMISe, and ARISE. Crit Care. 2016;20(1):160

7. De Backer D, Vincent JL. Early goal-directed therapy: do we have a definitive answer? Intensive Care Med. 2016;42(6):1048-50.
8. Oda S, Aibiki M, Ikeda T, et al. The Japanese guidelines for the management of sepsis. J Intensive Care. 2014:2(1):55.

9. Dellinger RP, Levy MM, Rhodes A, et al. Surviving sepsis campaign: international guidelines for management of severe sepsis and septic shock: 2012. Crit Care Med. 2013;41(2):580-637.

10. Jones AE, Shapiro NI, Trzeciak S, et al. Lactate clearance vs central venous oxygen saturation as goals of early sepsis therapy: a randomized clinical trial. JAMA. 2010;303(8):739-46.

11. PRISM Investigators, Rowan KM, Angus DC, et al. Early, goal-directed therapy for septic shock - a patient-level meta-analysis. N Engl J Med. 2017;376(23): 2223-34.

12. Cecconi M, De Backer D, Antonelli M, et al. Consensus on circulatory shock and hemodynamic monitoring. Task force of the European Society of Intensive Care Medicine. Intensive Care Med. 2014;40(12):1795-815.

13. Eskesen TG, Wetterslev M, Perner A. Systematic review including re-analyses of 1148 individual data sets of central venous pressure as a predictor of fluid responsiveness. Intensive Care Med. 2016;42(3):324-32.

14. Kelm DJ, Perrin JT, Cartin-Ceba R, et al. Fluid overload in patients with severe sepsis and septic shock treated with early goal-directed therapy is associated with increased acute need for fluid-related medical interventions and hospital death. Shock. 2015;43(1):68-73.

15. Levy MM, Evans LE, Rhodes A. The surviving sepsis campaign bundle: 2018 update. Crit Care Med. 2018;46(6):997-1000.

\section{Ready to submit your research? Choose BMC and benefit from:}

- fast, convenient online submission

- thorough peer review by experienced researchers in your field

- rapid publication on acceptance

- support for research data, including large and complex data types

- gold Open Access which fosters wider collaboration and increased citations

- maximum visibility for your research: over $100 \mathrm{M}$ website views per year

At $\mathrm{BMC}$, research is always in progress.

Learn more biomedcentral.com/submissions 